\title{
LA CONSTITUCIONALIZACIÓN DE LA JUSTICIA TRANSICIONAL EN COLOMBIA
}

\author{
CARLOS FELIPE RÚA DELGADO
}

(C) UNED. Revista de Derecho Politico

N.o 111, mayo-agosto 2021 
SUMARIO

INTRODUCCIÓN. 1. EL ANÁLISIS DEL PRECEDENTE CONSTITUCIONAL. 2. EL CONCEPTO DE JUSTICIA TRANSICIONAL EN LA JURISPRUDENCIA CONSTITUCIONAL COLOMBIANA. 3. CONCLUSIONES. 4. BIBLIOGRAFÍA. 


\title{
LA CONSTITUCIONALIZACIÓN DE LA JUSTICIA TRANSICIONAL EN COLOMBIA
}

\author{
CARLOS FELIPE RÚA DELGADO*
}

Profesor tiempo completo de la Universidad de San Buenaventura - Cali, Colombia Doctorando en Ciencias Sociales y Jurídicas, Universidad Rey Juan Carlos, Madrid, España.

\section{INTRODUCCIÓN}

La justicia transicional fue introducida al ordenamiento jurídico colombiano con la expedición de la Ley 975 de $2005^{1}$, más conocida como Ley de Justicia y Paz, la cual surgió en el marco de las negociaciones entre el gobierno nacional y los grupos paramilitares que para ese entonces se encontraban federados en la organización criminal denominada Autodefensas Unidas de Colombia (AUC)², y correspondió al primer intento normativo, por parte del Estado colombiano, de incluir estándares internacionales en materia de verdad, justicia y reparación, en una norma jurídica diseñada para los actores del conflicto armado interno que ha padecido Colombia desde hace

* Abogado, Universidad Santiago de Cali, Colombia y magíster en Educación Superior de la misma universidad. Doctorando en Ciencias Sociales y Jurídicas, Universidad Rey Juan Carlos, Madrid, España. Profesor de tiempo completo e investigador de la Universidad de San Buenaventura, Cali, Colombia. Líder del Grupo de Investigación Problemas Contemporáneos del Derecho y la Política (Gipcodep) de la Universidad de San Buenaventura, Cali, categoría A en Colciencias. Investigador categorizado como Asociado por Colciencias. Correo: cfrua@usbcali.edu.co. Orcid: https://orcid.org/00000002-8915-8968

1 CONGRESO DE COLOMBIA. Ley 975 de 2005, «Por la cual se dictan disposiciones para la reincorporación de miembros de grupos armados organizados al margen de la ley, que contribuyan de manera efectiva a la consecución de la paz nacional y se dictan otras disposiciones para acuerdos humanitarios». Disponible en: http://www.secretariasenado.gov.co/senado/basedoc/ley_0975_2005.html

2 RÚA DELGADO, C. F., (2014). «Prolegómenos para la aplicación de criterios de priorización de delitos en los procesos de Justica y Paz en Colombia», Revista Latinoamericana de Derechos Humanos, Vol. 25, No. 2, pág. 198. 
décadas ${ }^{3}$. A partir de ahí, la justicia transicional se fue afianzando en el ordenamiento colombiano hasta convertirse en un elemento esencial en la búsqueda de una salida negociada al conflicto ${ }^{4}$. Aun cuando inicialmente la justicia transicional se adoptó a través de leyes (Ley 975 de 2005, Ley 1448 de 20115), solamente a partir del inicio del proceso de negociación entre el gobierno y la guerrilla de las FARC (Fuerzas Armadas Revolucionarias de Colombia) se puede hablar de la constitucionalización de la justicia transicional ${ }^{6}$, cuando se expidió el Acto Legislativo ${ }^{7} 01$ de $2012^{8}$, más conocido como Marco Jurídico para la Paz, cuyo propósito era brindarle un asidero constitucional a los nacientes diálogos de paz. Aun cuando el Acuerdo Final con las FARC $^{9}$ posteriormente fue objeto de tratamiento constitucional, al ser incorporadas normas superiores tendientes a establecer los instrumentos jurídicos sobre los que se asentaría la implementación de lo acordado ${ }^{10}$, lo cierto es que ese Marco Jurídico para la Paz sirvió como base, no sólo para que la justicia transicional se asumiera como una categoría constitucional, sino que a partir de ahí se estructuró una jurisprudencia constitucional que comenzó a conceptualizar respecto de las tensiones entre este modelo de justicia con principios como la paz, la obligación de persecución de crímenes y la superación del conflicto armado en el marco de un Estado Social de Derecho, lo que hizo de la Corte Constitucional una de las voces más importantes en el proceso de consolidación, no sólo de los acuerdos, sino del proceso de constitucio-

3 Ver: PÉREZ TORO, W. F. (2000). «Guerra y delito en Colombia», Revista Estudios Políticos, No. 12, pág. 14.

4 Para una revisión del devenir de la justicia transicional en Colombia ver: RÚA DELGADO, C. F. (2015). «Los momentos de la justicia transicional en Colombia», Revista de Derecho, No. 43, págs. 71-109.

5 CONGRESO DE COLOMBIA. Ley 1448 de 2011, «Por la cual se dictan medidas de atención, asistencia y reparación integral a las víctimas del conflicto armado interno y se dictan otras disposiciones».

6 RÚA DELGADO, Carlos Felipe (2015); ob. cit., pág. 93.

7 En Colombia la denominación de Acto Legislativo está reservada a las reformas constitucionales.

8 CONGRESO DE COLOMBIA. Acto Legislativo 01 de 2012, «Por medio del cual se establecen instrumentos jurídicos de justicia transicional en el marco del artículo 22 de la Constitución Política y se dictan otras disposiciones».

9 Acuerdo Final para la terminación del conflicto y la construcción de una paz estable y duradera (noviembre 24 de 2016).

10 Acto Legislativo 01 de 2012, «Por medio del cual se establecen instrumentos jurídicos de justicia transicional en el marco del artículo 22 de la Constitución Política y se dictan otras disposiciones». Acto Legislativo 01 de 2016, «por medio del cual se establecen instrumentos jurídicos para facilitar y asegurar la implementación y el desarrollo normativo del acuerdo final para la terminación del conflicto y la construcción de una paz estable y duradera». Acto Legislativo 01 de 2017, «por medio del cual se crea un título de disposiciones transitorias de la Constitución para la terminación del conflicto armado y la construcción de una paz estable y duradera y se dictan otras disposiciones». Acto Legislativo 02 de 2017, «por medio del cual se adiciona un artículo transitorio a la Constitución con el propósito de dar estabilidad y seguridad jurídica al acuerdo final para la terminación del conflicto y la construcción de una Paz Estable y Duradera». Acto Legislativo 03 de 2017, «por medio del cual se regula parcialmente el componente de reincorporación política del Acuerdo Final para la Terminación del Conflicto y la Construcción de una Paz Estable y Duradera por medio del cual se regula parcialmente el componente de reincorporación política del Acuerdo Final para la Terminación del Conflicto y la Construcción de una Paz Estable y Duradera». 
nalización de la justicia transicional ${ }^{11}$, particularmente con la copiosa jurisprudencia emitida durante los años posteriores a la firma del Acuerdo Final y que sirvieron para sentar las bases del Sistema Integral de Verdad, Justicia, Reparación y No Repetición, pactado en el punto 5 del Acuerdo y que originó la Jurisdicción Especial para la Paz.

Dado lo anterior el artículo se desarrollará en dos acápites concretos. En el primero se abordará el análisis del precedente constitucional como metodología para el estudio de las sentencias por medio de la elaboración de líneas jurisprudenciales. Se perfila este método como el mecanismo idóneo para identificar los elementos que determinan los diversos conceptos trabajados en la jurisprudencia, para el estudio que se realiza: la justicia transicional. En el segundo, se realiza el análisis propiamente dicho sobre las sentencias de la Corte Constitucional, entre los años 2002 y 2018, en las cuales se trabaja el concepto de justicia transicional teniendo en cuenta los dos sistemas que han surgido en Colombia teniendo este como fundamento, a saber: el Sistema de Justicia y Paz y el Sistema Integral de Verdad, Justicia, Reparación y No Repetición.

\section{EL ANÁLISIS DEL PRECEDENTE CONSTITUCIONAL}

El análisis del precedente jurisprudencial, particularmente el constitucional, ha tenido un desarrollo importante en los últimos años, en donde se destaca, particularmente, el trabajo desarrollado por Diego Eduardo López Medina ${ }^{12}$, quien logró articular una metodología de análisis de precedente a partir de la elaboración de líneas jurisprudenciales que, más que un estudio cronológico, implican el análisis sistemático de las posturas adoptadas en las rationes decidendi de las diferentes sentencias, con el fin de obtener un balance constitucional ${ }^{13}$.

El análisis del precedente jurisprudencial resulta importante en la medida en que, en virtud de la Constitución Política de 1991, el sistema savigniano de fuentes del derecho sufrió una reconfiguración que obligó al ascenso de la jurisprudencia en el sistema de fuentes formales del derecho ${ }^{14}$, en desmedro de la legalidad dominante ${ }^{15}$,

11 Ver: RÚA DELGADO, C. F. (2017). «Hermenéutica de la justicia transicional en Colombia: una lectura desde la teoría de los momentos de Lefebvre», Revista de Derecho Migratorio y Extranjería, No. 44, pág. 147.

12 Ver: LÓPEZ MEDINA, D. E. (2007). El derecho de los jueces, segunda edición, tercera reimpresión, Bogotá D.C., Legis; LÓPEZ MEDINA, D. E. (2006). Interpretación constitucional, Bogotá D.C., Consejo Superior de la Judicatura.

13 El balance constitucional es «una doctrina jurisprudencial vigente más o menos definida que sirva como regla de conducta y estándar de crítica a la actividad de jueces, funcionarios y litigantes interesados en aplicar el derecho jurisprudencial a casos futuros.» LÓPEZ MEDINA, D. E. (2007); ob. cit., pág. 140).

14 Ver: QUINCHE RAMÍREZ, M. F. (2014). El precedente judicial y sus reglas, Bogotá D.C., Legis, págs. 26-36.

15 «La adopción de un nuevo lenguaje y la toma de decisiones en el plano metodológico, relacionadas con la construcción de los fallos judiciales y sobre todo, con su recepción y la adopción de "un nuevo modelo de análisis jurisprudencial" por parte de un auditorio renovado y ampliado, conformado por los funcionarios judiciales, los

(C) UNED. Revista de Derecho Politico

N. ${ }^{\circ} 111$, mayo-agosto 2021, págs. 343-374 
lo que implicó, a su vez, que el precedente se convirtiese, por sí mismo en una nueva fuente del derecho ${ }^{16}$, que hizo del desconocimiento del precedente emanado de las cortes y - principalmente - del constitucional ${ }^{17}$, una causal de procedencia de la acción de tutela en contra de providencias judiciales ${ }^{18}$. La construcción de precedentes obligatorios termina generando, en cabeza de la Corte Constitucional, una tarea normativa, en tanto que, la estructuración de significados a los enunciados normativos, constituye por sí misma una tarea normativa ${ }^{19}$.

Como consecuencia directa de la conversión del precedente en fuente del derecho obligatoria, aparece la sanción como garantía de armonización del mismo, en aras de un deber de coherencia y de igualdad en el tratamiento jurídico, lo que debe verse reflejado en líneas jurisprudenciales estables ${ }^{20}$, generando por ello procesos de autocontrol que lleven a la estabilización de dichas líneas ${ }^{21}$, incluyendo la amenaza a los jueces que se aparten del precedente establecido, con una posible persecución penal por estar incursos, presumiblemente, en la conducta punible de prevaricato por acción, en donde se ha interpretado que, cuando el tipo penal habla de ajustarse a la ley, tam-

empleados judiciales, los demás servidores públicos, los abogados, los estudiantes de derecho y el público en general, quienes por primera vez reivindicaban su derecho a conocer y usar las sentencias, los precedentes judiciales, en la medida en que estos contenían abora el derecho vigente, es decir, reglas jurídicas de aplicación inmediata y obligatoria.» QUINCHE RAMÍREZ, M. F. (2014); ob. cit., pág. 36.

16 Ver: LÓPEZ CUÉLLAR, N. (2015). Pluralismo jurídico estatal: entre conflicto y diálogo. Enseñanzas de un caso colombiano, Bogotá D.C., Universidad del Rosario, págs. 164-167. En un sentido contrario puede revisarse BARZOTTO, L. (2013). «Positivismo, neoconstitucionalismo y activismo judicial». En MORA, G. y BENÍTEZ, V. (Coordinadores), Retos del derecho constitucional contemporáneo. Editorial Astrea, págs. 51-78; que exponen, desde la descripción kelseniana de la aplicación judicial del derecho, «(...) la sentencia, norma individual, es producida por un acto de voluntad que elige, entre diversas posibilidades contenidas en el interior de la norma general a ser aplicada, (...). Esto puede llevar a la conclusión de que, si el juzgador elige un contenido para la norma individual que no esté virtualmente en "contenido» en la norma general, producirá una norma individual invalida.»., pág. 58.

17 Ver: MONTOYA MEDINA, L. E. (2016). El imperio de la jurisprudencia, Bogotá D.C., Grupo Editorial Ibáñez, págs. 157-160.

18 Ver: QUINCHE RAMÍREZ, M. F. (2010). Vías de becho: acción de tutela contra providencias judiciales, sexta edición, Bogotá D.C., Ediciones Doctrina y Ley Ltda., págs. 241-244.

19 GRÁNDEZ CASTRO, P. (2016). El Ascenso de los principios en la práctica constitucional, Lima, Palestra Editores, pág. 119.

20 «El respeto al precedente judicial es tan importante que la Corte Constitucional tiene sentencias en las que reafirma y reitera de manera muy clara la necesidad de coherencia de los fallos judiciales de instancia con las líneas jurisprudenciales estables. Estos esfuerzos son notorios, por ejemplo, en las recientes sentencias SU-053/15 y T-309/15.» LÓPEZ MEDINA, D. E. (2016). Eslabones del Derecho. El deber de coherencia con el precedente judicial, Bogotá D.C., Legis, pág. 81.

21 «Pero aún hay más: otra forma que tiene la Corte Constitucional de monitorear el respeto del precedente judicial es a través de la admisión y decisión de las nulidades presentadas por los intervinientes en los procesos ante la Corte en contra de sus propias sentencias. Este mecanismo permite un control interno de la eventual incoherencia jurisprudencial entre sus propias salas (auto-precedente), mientras que el mecanismo ordinario que se acaba de describir (la tutela contra sentencias judiciales) apunta a un control externo de los jueces, funcionarios públicos e incluso particulares (precedente vertical).»Ibidem, pág. 82. 
bién se entiende como ajuste al precedente, en un sentido amplio ${ }^{22}$, lo cual podría acarrear problemas de imputación por no cumplir con el requisito de tipicidad estricta.

En el caso de la justicia transicional se hace palpable la dimensión política del tribunal constitucional, en tanto que la naturaleza de sus decisiones, si bien son jurídicas y son argumentadas desde lo jurídico, el contexto político en referencia al decurso de los procesos políticos definitorios de la vida nacional - como un proceso de paz, por ejemplo - es necesariamente tenido en la cuenta por la jurisprudencia constitucional $^{23}$, dado que no se trata simplemente del pronunciamiento sobre juicios hipotéticos, sino sobre aspectos fundamentales para el devenir histórico del Estado. Esta dimensión política resultó particularmente relevante en el control de constitucionalidad ${ }^{24}$ efectuado al nuevo mecanismo de reforma de la Constitución introducido por el Acto Legislativo 01 de 2016, por medio del cual se creó un nuevo mecanismo, transitorio, de reforma denominado procedimiento legislativo especial, comúnmente conocido como fast track ${ }^{25}$. El fast track o vía rápida, significó que el Congreso se desprendiera temporalmente de sus funciones deliberativas en los procesos de reforma constitucional emanados del Acuerdo Final con las FARC y aprobara, en un trámite simplificado las propuestas presentadas por el Gobierno, en donde no se discutirían, por ejemplo, las minucias del texto sino una aprobación del mismo en bloque, en un intento por conservar la integralidad del mismo texto, además de obviarse una de las dos vueltas, para sumar ocho debates, que tradicionalmente se han dado en el Congreso para este tipo de reformas y se agotaran en una sola vuelta de cuatro debates, como si fuese el trámite de una ley.

22 Ibidem., págs. 83-97.

23 «Se hace evidente, así, la dimensión política del juez constitucional, no por su carácter electivo, el cual hoy carece de interés en el debate jurídico y político, sino por la naturaleza de sus decisiones, las cuales, si bien ostentan una génesis jurídica, su dimensión constitucional y su dimensión de decisión de poder las nota de una naturaleza política innegable.» SIERRA CADENA, G. (2009). El juez constitucional: un actor regulador de las políticas públicas, Bogotá D.C., Universidad del Rosario, pág. 169.

24 «En diversas oportunidades la Corte ha hecho referencia al control constitucional en el sistema colombiano, cuyo propósito es «hacer efectivo el imperio del ordenamiento fundamental», identificando al menos tres elementos que lo hacen instrumento vital en la protección de la norma normarum. Como primer elemento, el surgimiento de la justicia constitucional a partir de «la necesidad de controlar y limitar el ejercicio del poder político en beneficio de la normatividad de la Constitución», así como también para proteger los derechos contenidos en ella en cuanto fundamento «de toda comunidad organizada, de la paz, de la convivencia pacífica y de la justicia.» Como segundo elemento, la justicia constitucional es resultado de la evolución socio-política en una democracia consolidada, y a través de tal jurisdicción se conforma «un sistema de defensa de la Constitución, impidiendo que la violación directa de la misma o el desconocimiento de sus reglas pase inadvertido». En suma es "consecuencia necesaria y obvia del carácter normativo de la Carta, (la cual es) pilar fundamental del proceso político y de la vida social.»Y un tercer elemento descansa en que la justicia constitucional se establece "para asegurar el respeto de las normas básicas constitucionales, tanto las orgánicas como las dogmáticas.» GONZÁLEZ QUINTERO, R. y MORENO ORTÍZ, L. J. (2018). «Funciones secundarias de la Corte Constitucional colombiana: una aproximación a la decisión sobre excusas a los emplazamientos cursados por el Congreso», Revista de Derecho Político, No. 102, pág. 378.

25 QUINCHE RAMÍREZ, M. F. (2017). Reformismo constitucional, Bogotá D.C., Grupo Editorial Ibáñez, págs. 191-197.

(C) UNED. Revista de Derecho Político

N. ${ }^{\circ} 111$, mayo-agosto 2021, págs. 343-374 
Este tipo de reformas hubiese resultado impensable en un contexto diferente, entiéndase en tiempos normales, en donde no estuviese en juego el futuro de un acuerdo de paz para un Estado que ha padecido décadas de conflicto armado, pero en este caso la Corte prefirió declarar la exequibilidad bajo el entendido que el fast track correspondía a un engranaje dentro de una maquinaria mucho más grande que era todo el proceso de incorporación, al ordenamiento jurídico, de los pactos alcanzados en el Acuerdo Final, lo que demuestra la dimensión política de la decisión ${ }^{26}$. Un razonamiento similar puede aplicarse a las normas expedidas mediante el fast track y que tenían como propósito cimentar las bases del nuevo modelo de justicia transicional aplicable, de conformidad con lo acordado con las FARC ${ }^{27}$.

En la metodología de análisis jurisprudencial a partir de la construcción de líneas jurisprudenciales, esbozada por López Medina, lo primero corresponde a la identificación de los escenarios constitucionales con miras a lograr un correcto planteamiento del problema jurídico a resolver. Los escenarios constitucionales corresponden a los ámbitos de aplicación de un principio constitucional ${ }^{28}$. En el caso presente, el escenario es el de la justicia transicional. Posteriormente se aplica la metodología. Su paso inicial consiste en la identificación de la sentencia arquimédica ${ }^{29}$; esto es, seleccionar la sentencia más reciente sobre el tema investigado, esta permitirá la construcción de un nicho citacional, en donde se observan relaciones estructurales de otras sentencias. De manera consecuente, se aplica el proceso de ingeniería de reversa ${ }^{30}$, el cual consiste en hallar los argumentos de autoridad citados por el juez como fundamento de la decisión, dentro de la sentencia arquimédica. Ello permite la graficación del nicho citacional ${ }^{31}$, es decir, la

26 «Por todo lo cual, en conclusión, si bien el Acto legislativo 1 de 2016 autoriza al Congreso para producir actos legislativos en una sola vuelta con cuatro debates, esta es una pieza funcional dentro de un procedimiento especial de reforma con otros engranajes. Cuando todas las piezas del mecanismo se articulan puede observarse que: (i) su objetivo es lograr la paz, fin imperioso del orden constitucional a la vez que un modo de conservar su integridad, lo cual es a su turno lo que busca garantizarse con el principio específico de rigidez contemplado en la Carta de 1991; (ii) constituye un mecanismo especial, excepcional y transitorio de reforma, que adiciona un procedimiento a los previstos en las cláusulas de enmienda constitucional, que no son intangibles; (iii) dentro del marco de la reforma, los procedimientos de expedición de actos legislativos y de leyes se diferencian entre sí por sus distintos niveles de dificultad; y (iv) fuera del Acto Legislativo, el mecanismo especial de enmienda constitucional mantiene el nivel de resistencia al cambio de las normas constitucionales por encima del de las leyes, no petrifica las cláusulas de reforma de la Constitución, no suprime ni reduce la diversidad en los mecanismos de enmienda o sus formas de activación, ni tampoco equipara el poder constituyente a la competencia de revisión constitucional. Estas variaciones en modo alguno remplazan por uno distinto el principio de resistencia constitucional relativa, variable, diversa y funcionalmente diferenciada. Por el contrario, se ajustan al marco constitucional prexistente. De manera que no encuentra la Corte un vicio de competencia por sustitución.» CORTE CONSTITUCIONAL. (2016-B). Sentencia C-699. [M.P. María Victoria Calle Correa].

27 QUINCHE RAMÍREZ, M. F. (2017); ob. cit., págs. 204-214.

28 López Medina define al escenario constitucional como «el patrón fáctico típico (con su correspondiente campo de intereses contrapuestos) en el que la Corte ha especificado, mediante subreglas, el significado concreto de un principio constitucional abstracto». LÓPEZ MEDINA, D. E. (2007); ob. cit., pág. 148.

29 Ibidem.

30 Ibidem.

31 Ibidem. 
construcción de un diagrama en donde se evidencien los puntos nodales de jurisprudencia, entendiendo por éstos, la conexión estructural entre las citas identificadas, ello hace posible caracterizar específicamente el escenario constitucional. Es importante tener como aspecto central la similitud entre los hechos o patrones fácticos y consideraciones que fundamentan las rationes decidendi de las decisiones judiciales aquí agrupadas. El propósito principal de la graficación del nicho citacional es la identificación de sentencias hito ${ }^{32}$, en tanto que de allí se extraen las citas de argumentos esenciales para las decisiones analógicas, por ende, se trata de sentencias citadas de manera constante, entonces se constituyen como el repertorio frecuente que permite la retórica y el marco de análisis de la categoría o problema jurídico estudiado.

Respecto de la tipología de hitos definida por López Medina, en primer lugar, se encuentran las sentencias fundacionales ofundadoras de linea, las cuales se caracterizan por ser las primeras en establecer claridad argumentativa desde parámetros concretos frente a problemas jurídicos delimitados, es decir, se trata de los primeros fallos en «llenar» el vacío jurisprudencial frente a ciertos temas, estas también dan apertura al estudio de dichas categorías. En segundo lugar, se encuentran las sentencias consolidadoras de linea, que son las que permiten a la Corte la definición de una subregla por vía de autoridad ${ }^{33}$. El tercer tipo de hito jurisprudencial corresponde a las sentencias reconceptualizadoras de línea, las cuales corresponden a reconstrucciones conceptuales realizadas $5 \mathrm{C}$ por la Corte a partir de ejercicios interpretativos de las diferentes rationes decidendi de los fallos que componen la línea, de donde se extractan nuevas teorías o interpretaciones. El último tipo de hito jurisprudencial corresponde a la sentencia dominante $e^{34}$, es decir, aquella que es citada con frecuencia por contener los criterios vigentes y dominantes de la línea. Las sentencias dominantes suelen ser de cualquier tipo de hito, menos de las fundadoras de línea.

En relación con lo expuesto, es de relevancia indicar que es imprescindible la delimitación idónea del problema jurídico o de las categorías frente a las cuales se requiera conocer las tendencias y rupturas en la práctica judicial, centrada en su práctica argumentativa citacional.

32 "Una "sentencia bito" es aquella que pertenece al repertorio frecuente de sentencias que la Corte cita en fallos subsiguientes y que proveen la retórica y marco de análisis en el tema concreto que se estudia.» Ibidem., pág. 171.

33 «Las sentencias hito consolidadoras de línea son aquéllas en las que la Corte trata de definir con autoridad una subregla de derecho constitucional y en la que usualmente se decanta un balance constitucional más complejo que el que en un comienzo fue planteado por las sentencias fundadoras de línea.» Ibidem., págs. 164-165.

34 «Se trata de aquella sentencia que, según el analista, contiene los criterios vigentes y dominantes, por medio de los cuales la Corte Constitucional resuelve un conflicto de intereses dentro de determinado escenario constitucional». Ibidem., págs. 165 .

N. ${ }^{\circ} 111$, mayo-agosto 2021, págs. 343-374 


\section{EL CONCEPTO DE JUSTICIA TRANSICIONAL EN LA JURISPRUDENCIA CONSTITUCIONAL COLOMBIANA}

La justicia transicional corresponde a un paradigma jurídico, en tanto que se trata de una respuesta dada por el Derecho ${ }^{35}$ a la cuestión de cómo resolver la tensión propia entre paz e impunidad que se presenta como obstáculo en la resolución de los conflictos, por lo que la fórmula frecuente de las amnistías o indultos generalizados ${ }^{36}$, como forma recurrente de solucionar los conflictos, termina sacrificando los derechos de las víctimas y ponderando, con mucha frecuencia, la paz — entiéndase en este sentido como dejación de armas — sobre la justicia, lo que ha recreado escenarios de impunidad. Además de ello, corresponde a un paradigma político que hace referencia a la transición en $s^{i 37}$. Por tal motivo uno de los propósitos principales de la justicia transicional corresponde a la necesidad de lograr ese equilibrio que comporte tanto el acceso a la justicia como la cimentación de las bases de una paz sostenible en el tiempo ${ }^{38}$. Para alcanzar tal cometido, la justicia transicional debe contemplar medidas de naturaleza judicial y no judicial ${ }^{39}$, con el fin de reparar el tejido social afectado y, sobre todo, que las víctimas sientan satisfechas sus necesidades de verdad, de justicia y de reparación para que no repliquen la espiral de violencia y pueda pensarse en una reconciliación que lleve a la consolidación del sistema democrático, es por ello que el elemento justicia de la justicia de transición debe comprenderse en sentido amplio ${ }^{40}$,

35 «La justicia transicional corresponde al conjunto de elementos jurídicos, bien sean judiciales o extrajudiciales, determinados en acatamiento de los estándares internacionales definidos en materia de verdad, justicia, reparación y garantías de no repetición, mediante los cuales se pretende lograr un tránsito en uno de los siguientes supuestos: de un estado de vulneración sistemática de derechos humanos a uno de cesación de dicha vulneración, de un régimen totalitario a un régimen democrático o de un estado de conflicto a uno de cesación del conflicto, que implique la construcción de un posconflicto. Es por ello que el concepto justicia transicional contiene dos referentes a saber: el jurídico y el político. El jurídico se refiere al cumplimiento de los estándares internacionales enunciados, mientras que el político implica la transición en sí.» RÚA DELGADO, C. F. (2016). «La justicia anamnética como construcción complementaria del paradigma de justicia transicional. Una mirada desde el caso colombiano», Revista ius et Praxis, Vol. 22, No. 1, pág. 458.

36 Ibidem., pág. 459.

37 Ibidem., pág. 458.

38 Ver: RÚA DELGADO, C. F., DUARTE MOLINA, T. M. y GÓMEZ MORALES, L. F. (2018). «Escenarios para el sometimiento de excluidos de Justicia y Paz a la Jurisdicción Especial para la Paz: disquisición sobre sus ámbitos de aplicación», Revista opinión Jurídica, Vol. 17, No. 35, pág. 122.

39 Ver: AMBOS, K. (2009). «El marco jurídico de la justicia de transición». En AMBOS, K., MALARINO, E. y ELSNER, G. (Editores), Justicia de Transición. Informes de América Latina, Alemania, Italia y España, pág. 23.

40 «El elemento justicia en la justicia de transición debe ser comprendido ampliamente. En consecuencia, justicia es »una idea de responsabilidad y equidad (fairness) en la protección y vindicación de derechos y la prevención y castigo de infracciones. Justicia implica consideración de los derechos del acusado, de los intereses de las víctimas y del bienestar de la sociedad a largo plazo. Es un concepto arraigado en todas las culturas y tradiciones nacionales y, aunque su administración implica usualmente mecanismos judiciales formales, son igualmente relevantes mecanismos tradicionales de resolución de conflictos». De este modo, justicia en la justicia de transición supone mucho más que justicia penal retributiva — se asume, de hecho, que la justicia penal no puede ser completamente administrada- 
no limitándose exclusivamente a la búsqueda de una retribución, sino de fórmulas restaurativas que involucren tanto protección de derechos como medidas de protección y de castigo por las infracciones cometidas ${ }^{41}$.

Como se indicó en líneas anteriores, en el caso colombiano la justicia de transición fue constitucionalizada, lo que convirtió a la Corte Constitucional en un actor fundamental para la definición del alcance y del ámbito de aplicación de dicho modelo de justicia $^{42}$. Mientras en el caso de la Ley de Justicia y Paz (Ley 975 de 2005), las delimitaciones conceptuales y del ámbito de aplicación corrieron por cuenta del legislador, en el caso del modelo de justicia transicional que surge con el Acuerdo Final con las FARC, le corresponderá al constituyente derivado y por ende a la Corte Constitucional, la tarea de realizar las definiciones conceptuales que permitan sentar las bases para la aplicación de dicho modelo a los casos concretos por parte de la Jurisdicción Especial para la Paz (JEP), la cual fue creada como consecuencia del mismo Acuerdo Final. En virtud de lo expuesto, el precedente constitucional será analizado a partir del método de construcción de líneas jurisprudenciales planteado por López Medina y que fue explicitado en líneas precedentes. De acuerdo con el método escogido, aun cuando podría pensarse que corresponde a un mero enlistamiento de sentencias, lo cierto es que estas deben enunciarse para efectos de, por una parte poder determinar los nichos citacionales $y$ así identificar los diferentes tipos de hitos jurisprudenciales, y por la otra, con el fin de establecer la coherencia y uniformidad de los planteamientos constitucionales, que en términos de López Medina se considera como balance constitucional ${ }^{43}$; en tal sentido se propugna por la visualización de la sombra decisional ${ }^{44}$, y por ende poder identificar cuáles sentencias se alejan de esta. Esto per-

y abarca a la justicia restaurativa en cuanto apunta a restaurar o incluso reconstruir la comunidad (en el sentido de justicia «creativa»). En última instancia, la justicia de transición es una justicia de excepción que aspira a cambiar la situación de conflicto o posconflicto «de un peor a un mejor estado».» Ibidem., pág. 28.

41 «Entonces, el elemento justicia en la justicia de transición se debe comprender de manera amplia: una idea de responsabilidad y equidad en la protección y vindicación de derechos y la prevención y castigo de infracciones.» RÚA DELGADO, C. F., DUARTE MOLINA, T. M. y GÓMEZ MORALES, L. F. (2018); ob. cit., p. 122.

42 «La elevación a rango constitucional de la JT no solo es aceptada por la Corte, sino que en la sentencia analizada se establecen algunos aspectos fundamentales para la comprensión de la categoría JT en el modelo constitucional. Por un lado, la declaración de los derechos de las víctimas como derechos constitucionales y, por otro lado, el concepto de JT conforme a la idea de un modelo bolístico en donde el juez constitucional debe encontrar un balance entre los intereses y valores enfrentados.» AMBOS, K. y ZULUAGA, J. (2014). "Justicia de transición y Constitución. A manera de introducción». En AMBOS, K. (Coordinador), Justicia de transición y Constitución. Análisis de la sentencia C-579 de 2013 de la Corte Constitucional. Temis Editorial, pág. 10.

43 «El "balance constitucional", una vez más, consiste en lo siguiente: la idea estricta del precedente parecería exigir que el siguiente fallo de un caso análogo dentro de una línea precedencial bien definida tendría que caer "en el mismo sitio".». LÓPEZ MEDINA, D. E. (2007). El derecho de los jueces, segunda edición, tercera reimpresión, Bogotá D.C., Legis, pág. 144.

44 «La doctrina del precedente exige que el siguiente fallo caiga dentro de la sombra decisional del fallo anterior, sin que tenga que coincidir exactamente con él. Esta amplitud es fruto de la utilización de diferentes técnicas de interpretación del precedente y permite la acomodación de diferentes matices de opinión individuales dentro de una corte colegiada.» Ibidem., pág. 144.

(C) UNED. Revista de Derecho Politico

N. ${ }^{\circ} 111$, mayo-agosto 2021, págs. 343-374 
mite revisar la cohesión de la línea jurisprudencial a partir de su argumentación. Para la elaboración de esta línea jurisprudencial se ha partido de la identificación de los elementos esenciales que se han presentado en la construcción del concepto de justicia transicional en relación con el alcance de éste como problema jurídico, para el cual se encuentra el siguiente nicho citacional:

\begin{tabular}{|c|c|c|c|}
\hline 2002 & 2003 & 2004 & 2005 \\
\hline C-578/04 & $\begin{array}{l}\text { C- } 004 / 03 \\
\text { C- } 871 / 03\end{array}$ & ---- & ---- \\
\hline 2006 & 2007 & 2008 & 2009 \\
\hline C-370/06 & ---- & C-1199/08 & ---- \\
\hline 2010 & 2011 & 2012 & 2013 \\
\hline $\begin{array}{c}\text { C-936/10. } \\
\text { Salvamento De Voto: } \\
\text { Humberto ANTONio Sierra } \\
\text { Porto } \\
\text { Mauricio GonZÁlez } \\
\text { Cuervo } \\
\text { Juan Carlos HenaO }\end{array}$ & C-771/11 & $\begin{array}{l}\text { C-052/12 } \\
\text { C-250/12 } \\
\text { C-781/12 }\end{array}$ & $\begin{array}{l}\text { C-280/13 } \\
\text { C-579/13 } \\
\text { C-581/13 } \\
\text { C- } 912 / 13\end{array}$ \\
\hline 2014 & 2015 & 2016 & 2017 \\
\hline $\begin{array}{l}\text { C-180/14 } \\
\text { C-286/14 } \\
\text { C-577/14 }\end{array}$ & C-694/15 & $\mathrm{C}-379 / 16$ & $\begin{array}{l}\text { C- } 160 / 17 \\
\text { C- } 172 / 17 \\
\text { C-332/17 } \\
\text { C-518/17 } \\
\text { C-541/17 } \\
\text { C-555/17 } \\
\text { C-565/17 } \\
\text { C- } 674 / 17\end{array}$ \\
\hline \multicolumn{4}{|l|}{2018} \\
\hline $\begin{array}{l}\text { C-007/18 } \\
\text { C-025/18 } \\
\text { C-027/18 } \\
\text { C-080/18 }\end{array}$ & & & \\
\hline
\end{tabular}

Fuente: Elaboración propia.

En virtud de lo anterior, aplicando la ingeniería reversa durante la pesquisa, se ha hallado la sentencia fundadora de línea poco antes de la promulgación del sistema de Justicia y Paz implementado en el año 2005 con la Ley 975, esta es la C-578 de 
$2002^{45}$ a través de la cual se estudió la constitucionalidad de la Ley 742 de $2002^{46}$, donde si bien no sé da un abordaje explícito al concepto de justicia transicional, sí se da respecto a los elementos individualmente considerados que, de fallo en fallo, lo han ido configurando. Así, se encuentra que, en esta sentencia, la Corporación explica la importancia de la Corte Penal Internacional (CPI) y explica la importancia de esta refiriéndose a varios asuntos relevantes al momento de diseñar mecanismos legales de justicia de transición ${ }^{47}$. Aunado a ello, la Corporación se referiría a la importancia de la lucha contra la impunidad, y a los derechos a la verdad, la justicia y la reparación en relación con las graves violaciones a los derechos humanos; reconociendo estos como el angular de la justicia transicional ${ }^{48}$.

Se advierte la importancia, como antecedente jurisprudencial, de las consideraciones de la sentencia C-578 de 2002 en relación con el papel de la paz como valor constitucional, así como las instituciones de la amnistía, e indultos como los mecanismos de su consolidación; además de los delitos y circunstancias ante las cuales estos no se pueden aceptar por traer consigo efectos contrarios a los elementos de la justicia de transición como al implicar impunidad y el desconocimiento del derecho a la verdad, la justicia y la reparación ${ }^{49}$.

45 CORTE CONSTITUCIONAL. (2002). Sentencia C-578. [M.P. Manuel José Cepeda Espinosa].

46 CONGRESO DE LA REPÚBLICA DE COLOMBIA. Ley 752 de 2002, «Por medio de la cual se aprueba el Estatuto de Roma de la Corte Penal Internacional, hecho en Roma, el día diecisiete (17) de julio de mil novecientos noventa y ocho (1998)».

47 "(...) marca un bito en la construcción de instituciones internacionales para proteger de manera efectiva el núcleo de derechos mínimos, mediante juicios de responsabilidad penal individual.» CORTE CONSTITUCIONAL. (2002); ob. cit.

48 "(...) evitar la impunidad de los detentadores transitorios de poder o de los protegidos por ellos, hasta la más alta jerarquía, y garantizar la efectividad de los derechos de las víctimas y perjudicados a conocer la verdad, a obtener justicia y a recibir una reparación justa por los daños que dichas conductas les han ocasionado, a fin de que dichas conductas no se repitan en el futuro.» Ibidem.

49 «En primer lugar, la Corte constata que la paz ocupa un lugar principalísimo en el orden de valores protegidos por la Constitución. Dentro del espíritu de que la Carta Política tuviera la vocación de ser un tratado de paz, la Asamblea Constituyente protegió el valor de la paz de diferentes maneras en varias disposiciones. Por ejemplo, en el Preámbulo la paz figura como un fin que orientó al constituyente en la elaboración de toda la Constitución. En el artículo 2 dicho propósito nacional cardinal se concreta en un fin esencial del Estado consistente en "asegurar la convivencia pacífica y la vigencia de un orden justo". Además, el artículo 22 va más lejos al establecer que "la paz es un derecho y un deber de obligatorio cumplimiento». Dentro de los múltiples instrumentos para facilitar el logro de la paz, la Constitución reguló procedimientos de resolución institucional de los conflictos y de protección efectiva de los derechos fundamentales, como la acción de tutela (artículo 86 CP.). Además, sin circunscribirse a un proceso de paz, la Constitución permite que "por graves motivos de conveniencia pública» se concedan amnistías o indultos por delitos políticos y estableció requisitos claros para que ello se ajuste a la Carta, dentro de los cuales se destacan que (i) el órgano que los concede sea el Congreso de la República donde concurren las diversas fuerzas políticas que representan a la Nación, (ii) que la decisión correspondiente sea adoptada por una mayoría calificada de los dos tercios de los votos de los miembros de una y otra cámara, (iii) que los delitos objeto de estos beneficios pertenezcan a la categoría de "delitos políticos» y (iv) que en caso de que los favorecidos fueren eximidos de la responsabilidad civil respecto de particulares, "el Estado quedará obligado a las indemnizaciones a que bubiere lugar» (artículo 150, numeral 17, CP). además, corresponde al gobierno en relación con la rama judicial conceder

N. ${ }^{\circ} 111$, mayo-agosto 2021, págs. 343-374 
Posteriormente, y en el interregno entre la Ley 742 de 2002 y la Ley 975 de 2005, se dio lugar a dos pronunciamientos de la Corte Constitucional sobre elementos de la justica transicional, sin que se llegara a profundizar en dicho concepto. Dentro de estas sentencias se hallan la C-004 de 2003- $\mathrm{A}^{50}$ sobre los derechos de las víctimas y la C-871 de $2003-\mathrm{B}^{51}$ sobre los derechos de las personas desplazadas por el conflicto armado.

La Corte Constitucional, tras la promulgación de la Ley 975 de 2005, mediante la sentencia C-370 de $2006^{52}$, por la cual se demanda la constitucionalidad integral de tal ley, se identifica la justicia transicional como un elemento necesario para alcanzar la paz, siendo esta entendida como presupuesto para la consolidación del Estado Social de Derecho; reconociendo, además, una tensión entre el objetivo social y el jurídico de ella; donde el primero plantea el lograr un tránsito efectivo hacia la paz o la democracia; y, el segundo — comprendido por los derechos de las víctimas - contiene la necesidad de investigación, juicio y castigo por parte del Estado respecto a las violaciones de derechos. La resolución de esta tensión es la que ha llevado a dicha Corporación al desarrollo conjunto de los elementos mínimos que componen la justicia transicional para plantear un concepto ${ }^{53}$.

No obstante, el pronunciamiento no define lo que es la justicia de transición, se limita a extraer la noción de ella dada por el Secretario General de las Naciones Unidas en su informe del 2004 $4^{54}$. Hasta este momento, la Corte Constitucional había identificado tres elementos angulares respecto de la justicia transicional: verdad, justicia y reparación; por lo anterior y lo expuesto en líneas anteriores sobre el contenido de esta sentencia, se puede identificar aquella como la sentencia dominante de la línea jurisprudencial. Empero, tomando como base tal sentencia, y ahora ante una nueva demanda de inconstitucionalidad a la Ley 975 de 2005, esta Corporación en la sentencia C-1199 de $2008^{55}$ identificó un cuarto elemento: la reconciliación, desde las nociones minimalista y maximalista; la primera enfocada en la tolerancia obligada o

los indultos por delitos políticos, con arreglo a la ley e informar al Congreso sobre el ejercicio de esta facultad (artículo 201, numeral 2, CP).» Ibidem.

50 CORTE CONSTITUCIONAL. (2003-A). Sentencia C-004. [M.P. Eduardo Montealegre Lynett].

51 CORTE CONSTITUCIONAL. (2003-B). Sentencia C-871. [M.P. Clara Inés Vargas Hernández].

52 CORTE CONSTITUCIONAL. (2006). Sentencia C-370. [Ms.Ps. Manuel José Cepeda Espinosa; Jaime Córdoba Triviño; Rodrigo Escobar Gil; Marco Gerardo Monroy Cabra; Álvaro Tafur Galvis; Clara Inés Vargas Hernández].

53 «(...) partiendo de la base de que los compromisos de los Estados en el respeto de los Derechos Humanos no se suspenden ni interrumpen por las circunstancias de transición, formula ciertos lineamientos a fin de asegurar estándares mínimos en materia de justicia, verdad y reparación.» Ibidem.

54 «(...) abarca toda la variedad de procesos y mecanismos asociados con los intentos de una sociedad por resolver los problemas derivados de un pasado de abusos a gran escala, a fin de que los responsables rindan cuentas de sus actos, servir a la justicia y lograr la reconciliación.» Tales mecanismos, agregó, "pueden ser judiciales o extrajudiciales, y tener distintos niveles de participación internacional (o carecer por completo de ella) así como abarcar el enjuiciamiento de personas, el resarcimiento, la búsqueda de la verdad, la reforma institucional, la investigación de antecedentes, la remoción del cargo o combinaciones de todos ellos.» Ibidem.

55 CORTE CONSTITUCIONAL. (2008). Sentencia C-1199. [M.P. Nilson Pinilla Pinilla]. 
por resignación, donde quienes fueron actores del conflicto se comprometen a no agredirse, aun cuando se presenten sentimientos de enemistad y odio; la segunda supone el perdón, un olvido casi artificial de rencores y desavenencias. Resalta el fallo que la Ley 975 de 2005, entendida como un instrumento de la justicia transicional tras implementar el sistema de Justicia y Paz, afronta dificultades en relación con su efectividad, pues al sentir de la población colombiana para ese momento histórico el país no se encuentra en una etapa de transición en el conflicto, sino en una nueva fase de él con la eliminación y aparición de nuevos y viejos actores.

Extiende esta Corporación su análisis sobre los componentes del elemento reparación de la justicia transicional englobando dentro de él las acciones encaminadas a la restitución, indemnización, rehabilitación, satisfacción y garantías de no repetición. Acciones que deben estar encaminadas, precisamente, a colaborar con el proceso de reconciliación nacional. De allí que la Corte realizase un acercamiento más diáfano hacia los elementos de la justicia transicional y su concepto. Preceptúa, entonces, que se ha dado relieve a los derechos de verdad, justicia y reparación que, si bien no agotan el catálogo de derechos de las víctimas, sí constituyen la columna vertebral de tales garantías ${ }^{56}$.

En contraposición a los elementos sustanciales examinados, fue en la sentencia C-936 de $2010^{57}$, tras una evidente congestión en el sistema de Justicia y Paz, que se empezó a considerar un componente procedimental en el concepto y alcance de la justicia transicional. No obstante, es en los salvamentos de voto de este fallo en los que se considera lo manifestado desde la C-370 de 2006 pero no solamente desde el punto de vista sustancial. ${ }^{58}$ Pero, en su argumento contraviene respecto al actuar de la Corte en el reconocimiento de este elemento procedimental, pues si se explora en la sentencia C-370 de 2006, se entiende como un sistema que usa mecanismos de la justicia ordinaria con el propósito de racionalizar la utilización del aparato estatal en la persecución penal y asegurar el orden justo. Menciona, así, que una de las paradojas que se presenta ante esta permisión es la inaplicabilidad del indulto a los desmovilizados, de rangos altos y medios ${ }^{59}$. También como salvamento de voto a la sentencia

56 «(...) la verdad, la justicia y la reparación se erigen como bienes cardinales de toda sociedad que se funde en un orden justo y de pacífica convivencia, entre los cuales median relaciones de conexidad e interdependencia, de manera tal que: No es posible lograr la justicia sin la verdad. No es posible llegar a la reparación sin la justicia.» Ibidem.

57 CORTE CONSTITUCIONAL. (2010). Sentencia C-936. [M.P. Luis Ernesto Vargas Silva].

58 "Toda la argumentación contenida en la sentencia C-370 de 2006 que constituye precedente vinculante para esta misma Corte, consideró como acorde a la Constitución utilizar figuras e instituciones judiciales propias de procesos penales e incluso la reducción punitiva. Este argumento llevado al absurdo supone que existen figuras jurídicas propias de justicia transicional y otras que no.» Ibidem., salvamento de voto del magistrado Humberto Sierra Porto.

59 «(...) los crímenes cometidos por los grupos paramilitares o de autodefensa, no pueden ser calificados como delitos políticos, son delitos comunes y por ende, resulta improcedente las concesiones de amnistías o indultos. Pero tampoco se les puede aplicar el principio de oportunidad dentro de los procesos que adelanta la Fiscalía porque este principio es un instrumento que está previsto para la delincuencia y los delitos comunes, no para procesos de paz o de regularización.»Ibidem., salvamento de voto del magistrado Humberto Sierra Porto.

N. ${ }^{\circ} 111$, mayo-agosto 2021, págs. 343-374 
en cuestión, el magistrado Juan Carlos Henao expone que, si bien en la ratio decidendi de esta providencia considera un cambio en cuanto al principio de oportunidad operante en el sistema de justicia transicional implementado mediante Justicia y Paz, esos mismos argumentos causan una desarticulación en relación al funcionamiento del régimen; pues según sus propios objetivos, que no sólo debe operar con celeridad, prontitud y resultados, sino también con los recursos con que cuenta ${ }^{60}$.

En el año 2011, con la sentencia C-771 ${ }^{61}$, la Corte Constitucional realiza lo que a su criterio son precisiones sobre el concepto de justicia transicional, sus elementos y aplicabilidad, pero que en verdad corresponden a la reconceptualización de este, respecto de los fallos precedentes, teniendo en cuenta las interpretaciones que ha dado sobre el mismo. De allí que esta se considerada la sentencia reconceptualizadora de línea. Así, expresa que teniendo en cuenta los estudios doctrinales sobre la categoría, esta debe ser comprendida ampliamente, tomándola como una idea de responsabilidad y equidad en la protección y vindicación de derechos y la prevención y castigo de infracciones. Pues, la justicia implica la consideración de los derechos del acusado, de los intereses de las víctimas y del bienestar de la sociedad a largo plazo, dando aplicación tanto a mecanismos judiciales formales como, y en la misma proporción, a mecanismos tradicionales y novedosos de resolución de conflictos ${ }^{62}$.

A inicios del siguiente año, a través del fallo C-052 de $2012^{63}$, y siguiendo la ruta establecida en la reconceptualización realizada, la Corte Constitucional esboza que la justicia transicional puede entenderse como una institución jurídica por medio de la cual se pretende la integración de diversos esfuerzos, que son aplicables en las sociedades para enfrentar las secuelas de violaciones masivas y abusos generalizados o sis-

En el mismo sentido: «La Sentencia C-370 de 2006 mediante la cual se analizó la ley 975 de 2005, también llamada ley de Justicia y Paz, habia ya aceptado el esquema de justicia transicional, mediante el cual se lograría la verdad, la justicia y la reparación; ello conllevó a que los altos mandos y los mandos medios de los grupos al margen de la ley, fueran sometidos a un proceso penal para determinar su responsabilidad. Por el contrario, para los integrantes rasos de dichos grupos, se consideró acorde con la Constitución utilizar figuras e instituciones judiciales propias de procesos penales para extinguir la pena u otras formas similares como lo era el principio de oportunidad. Por lo tanto, la aplicación del principio de oportunidad a los desmovilizados de los grupos armados ilegales no desconocía la Constitución sino por el contrario era el desarrollo de un proceso de justicia transicional empezado por la ley 975 de 2005 y que era complementado por la ley 1312 de 2009. La posición jurídica adoptada por la mayoría lleva a la incoherencia de suponer que existen figuras exclusivas propias de la justicia transicional y otras que no.» Ibidem., salvamento de voto del magistrado Mauricio González Cuervo.

60 Ibidem., salvamento de voto del magistrado Juan Carlos Henao).

61 CORTE CONSTITUCIONAL. (2011). Sentencia C-771. [M.P. Nilson Pinilla Pinilla].

$62 \ll(. .$.$) puede observarse que la justicia transicional se ocupa de procesos mediante los cuales se realizan$ transformaciones radicales a una sociedad, bien sea que ésta se encuentre en conflicto o post conflicto, en la consecución de la paz, sufriendo y enfrentando grandes dilemas originados en la compleja lucha por el equilibrio entre la paz y la justicia. Ello se hace, principalmente, con el propósito de impedir que hechos acaecidos en el marco de un conflicto vuelvan a ocurrir, para lo cual su función se concentra en el conocimiento de la verdad y en la reparación, buscando asi dar respuesta a los problemas asociados a un legado de abusos de derechos bumanos en un contexto democrático y aplicando medidas, de naturaleza judicial o no judicial, a los responsables de los crímenes.» Ibidem.

63 CORTE CONSTITUCIONAL. (2012-A). Sentencia C-052. [M.P. Nilson Pinilla Pinilla]. 
temáticos en materia de derechos humanos, que han sido sufridos en el marco de un conflicto, hacia una etapa constructiva de paz, respeto, reconciliación y consolidación de la democracia, situaciones de excepción frente a lo que resultaría de la aplicación de las instituciones penales corrientes. Por lo anterior, y debido a la consecutiva aplicación de la regla en ella aplicada, este fallo es considerado como la sentencia dominante en el camino que recorre la Corte tras la reconceptualización desde el año 2011.

El siguiente pronunciamiento relevante en relación con el concepto y alcance de la justicia transicional por parte de la Corte Constitucional corresponde a la sentencia C-250 de $2012^{64}$ donde se da una definición que, si bien no es llamada así por la Corporación, se logran identificar las características o elementos que han constituido precedente y teniendo en cuenta, principalmente, la Ley 1448 de $2011^{65}$. Además de ello, en relación con los elementos que componen el concepto y alcance de esta figura, la Corte advierte que en la producción normativa que resulta de la implementación de ella es menester que prevalezcan los límites temporales, debido a que son ellos los que hacen alusión a la transición de un periodo histórico a otro; por lo tanto, las limitaciones temporales son una característica de esos cuerpos normativos.

Durante ese año, la Corporación profirió un segundo fallo, la sentencia C-781 de $2012^{66}$, en relación con la constitucionalidad de la Ley 1448 de 2011, conocida como Ley de Víctimas en el ordenamiento jurídico colombiano. En ella se trata de manera enfática la definición de la categoría víctima con referencia a los daños por infracciones ocurridas con ocasión del conflicto armado interno. Por lo anterior, la Corte reconoce otro elemento dentro del alcance de la justicia transicional, haciendo referencia a las víctimas; ya que este es un régimen en el cual no se puede equiparar tal categoría como una igual dentro del sistema jurídico ordinario de reparación de víctimas de hechos delictivos regulados como daños particulares, esto es, la diferencia entre aquellas víctimas de la delincuencia común y las que surgen en el contexto del conflicto armado para efectos de determinar la aplicabilidad de la Ley 1448 de 2011. Sin duda, expresa la Corte, esto lleva a entender que la justicia transicional no es tan solo un complemento de la justicia ordinaria. En vista de lo anterior, y los fallos precedentes, la Corte esboza de manera más contundente el concepto de justicia transicional en el entramado argumentativo de la sentencia C-781 de 2012. Allí plantea que, desde el punto de vista de la Ley 1448 de 2011 las normas de justicia transicional se refieren a un contexto de posconflicto y transición política ${ }^{67}$. De allí que, desde la consid-

64 CORTE CONSTituCiOnAL. (2012-B). Sentencia C-250. [M.P. Humberto Antonio Sierra Porto].

65 «(...) acciones concretas tanto de naturaleza judicial como administrativa, al igual que acciones de naturaleza social y económica, dirigidas a individuos como a colectivos, y destinadas a las víctimas de infracciones al DIH y de violaciones graves y manifiestas a las normas internacionales de derechos humanos, ocurridas con ocasión del conflicto armado interno». Ibidem.

66 CORTE CONSTITUCIONAL. (2012-C). Sentencia C-781. [M.P. María Victoria Calle Correa].

${ }^{67}$ «(...) donde se busca garantizar los derechos a la verdad, a la justicia y a la reparación de un conjunto específico de víctimas, como a los deberes de prevención, atención y protección de víctimas de hechos violentos y viola- 
eración sobre el elemento víctimas como individuo que percibió un daño por causa del conflicto, se busque satisfacer los derechos a las víctimas, los cuales van a aparecer ahora como garantías constitucionales, a la verdad, la justicia, la reparación y las garantías de no repetición ${ }^{68}$.

El legislativo colombiano, por su parte, en la mencionada Ley 1448 de 2011 sí consideró la definición de la categoría en estudio. Sin embargo, hasta este punto, la Corte Constitucional no ofrece de manera tajante una, pero sí ha identificado diferentes elementos de la categoría y su alcance. Elementos que a partir de los fallos del año 2013 irá compilando en búsqueda de una definición propia de la categoría y analizar su alcance, en razón del ya instaurado proceso de paz con las FARC, como ocurre con la sentencia C-280 de $2013^{69}$.

Consecuentemente, en el ámbito del proceso de paz con el grupo armado de las FARC y en el estudio de constitucionalidad del Acto Legislativo 01 de 2012, la Corte Constitucional por vez primera habla de manera certera sobre el concepto y alcance de la justicia transicional en la sentencia C-579 de $2013^{70}$, donde, en general, sistematiza los elementos identificados previos a este fallo. Manifiesta, entonces, que la justicia transicional está constituida por un conjunto de procesos de transformación social y política profunda, en los que se hace imperioso el uso de diversos mecanismos para resolver problemas derivados de un pasado de abusos a gran escala, con el fin de lograr la rendición de cuentas por parte de los responsables en relación con sus actos, y así mismo servir a la justicia y lograr la reconciliación ${ }^{71}$. Reconoce, además y teniendo en cuenta los argumentos de los intervinientes, que es una forma de justicia adaptada a sociedades que se reforman a sí mismas después de un periodo de violencia

torios de los derechos bumanos y del derecho internacional bumanitario que tienen una relación cercana y suficiente con el desarrollo del conflicto armado interno que subsiste en el país.» Ibidem.

68 «(...) hacer efectivo el goce de sus derechos a la verdad, la justicia y la reparación con garantía de no repetición, de modo que se reconozca su condición de víctimas y se dignifique a través de la materialización de sus derechos constitucionales». CORTE CONSTITUCIONAL. (2012-C); ob. cit.

69 "(...) una institución jurídica a través de la cual se pretende integrar diversos esfuerzos que aplican las sociedades para enfrentar las consecuencias de violaciones masivas y abusos generalizados o sistemáticos en materia de derechos humanos, sufridos en un conflicto, hacia una etapa constructiva de paz, respeto, reconciliación y consolidación de la democracia, situaciones de excepción frente a lo que resultaría de la aplicación de las instituciones penales corrientes. Según lo ha reconocido la jurisprudencia, la presencia de este elemento implica una consideración adicional que se ve reflejada en el contenido concreto de las instituciones diseñadas para resguardar y proteger en forma adecuada los derechos de las víctimas previstos en la Constitución y en los instrumentos internacionales sobre la materia que hacen parte del bloque de constitucionalidad.» CORTE CONSTITUCIONAL. (2013-A). Sentencia C-280. [M.P. Nilson Pinilla Pinilla].

70 CORTE CONSTITUCIONAL. (2013-B). Sentencia C-579. [M.P. Jorge Ignacio Pretelt Chaljub].

71 «(...) una institución jurídica a través de la cual se pretende integrar diversos esfuerzos, que aplican las sociedades para enfrentar las consecuencias de violaciones masivas y abusos generalizados o sistemáticos en materia de derechos humanos, sufridos en un conflicto, hacia una etapa constructiva de paz, respeto, reconciliación y consolidación de la democracia, situaciones de excepción frente a lo que resultaría de la aplicación de las instituciones penales corrientes. » Ibidem. 
generalizada de derechos humanos. Se entiende, de esta manera, como un sistema o tipo de justicia de características específicas, aplicables de manera excepcional ${ }^{72}$.

Para la Corte, esta justicia implica la articulación de una serie de medidas, judiciales y extrajudiciales, además de abarcar el enjuiciamiento de personas, el resarcimiento, la búsqueda de la verdad, la reforma institucional, la investigación de antecedentes, la remoción del cargo o la combinación de todas ellas. De manera consecuente con la ratio usada por la Corte y la implementación de las reglas allí planteadas en los fallos venideros, la sentencia C-579 de 2013 hace su vez de sentencia consolidadora de línea sobre el concepto y alcance de la justicia transicional, al fijar los elementos que componen la justicia transicional con miras a la consecución de una paz estable y duradera ${ }^{73}$.

Ahora bien, en la sentencia C-581 de $2013^{74}$, la Corte reitera de manera literal las consideraciones expresadas en la sentencia C-280 de 2013. No obstante, los fallos C-581 de 2013 y C-912 de 2013 75 , hacen parte del análisis de la Corporación frente a la sostenibilidad fiscal del sistema de Justicia y Paz debido a la reparación integral de las víctimas, esto constituiría en sí un nuevo elemento en cuanto al alcance del concepto, toda vez que la reparación hace parte del eje fundamental del mismo ${ }^{76}$. Posteriormente, la Corte Constitucional en sentencia C-180 de 201477, trae consigo una síntesis sobre el concepto de justicia transicional, derivado de los expuestos en los fallos C-052 de 2012 y C-579 de $2013^{78}$. Tras este fallo, donde fácilmente se

72 «La justicia transicional busca solucionar las fuertes tensiones que se presentan entre la justicia y la paz, entre los imperativos jurídicos de satisfacción de los derechos de las víctimas y las necesidades de lograr el cese de hostilidades. Para ello es necesario conseguir un delicado balance entre ponerle fin a las hostilidades y prevenir la vuelta a la violencia (paz negativa) y consolidar la paz mediante reformas estructurales y políticas incluyentes (paz positiva). Para cumplir con este objetivo central es necesario desarrollar unos objetivos especiales: (...) 6.1.1.1. Reconocimiento de las víctimas, (...) 6.1.1.3. La reconciliación, (...) 6.1.1.4. El fortalecimiento de la democracia (...)». Ibidem.

73 «En este sentido, los elementos de la justicia transicional son fundamentales para la consecución de una paz verdadera, a saber: (I) la verdad será una condición para la paz si hace imposible denegar pasadas justicias; (II) la verdad será una condición para la paz cívica mediante el screening de funcionarios y políticos que hayan colaborado con el régimen prestransicional (sic); (III) la justicia transicional será una condición para la paz si satisface las demandas de retribución; (IV) la justicia distributiva será una condición de una paz duradera si determina las causas del conflicto; $(V)$ justicia puede hacer evitar nuevos delitos pero hay que estimar si una paz a largo plazo justifica prolongar el conflicto.» Ibidem.

74 CORTE CONSTITUCIONAL. (2013-C). Sentencia C-581. [M.P. Nilson Pinilla Pinilla].

75 CORTE CONSTITUCIONAL. (2013-D). Sentencia C-912. [M.P. María Victoria Calle Correo].

76 «(...) en contextos de justicia transicional, donde está en juego la reparación de un gran número de víctimas, se pretenda hacer más eficiente el gasto público por la vía de asimilar o sustituir las prestaciones derivadas del deber de reparar, con aquellas que forman parte del cumplimiento de los deberes sociales del estado o de la estabilización socioeconómica de personas en situación de crisis humanitaria.»Ibidem.

77 CORTE CONSTITUCIONAL. (2014-A). Sentencia C-180. [M.P. Alberto Rojas Ríos].

78 «(...) se entiende el conjunto de berramientas jurídicas, políticas y sociales que se fijan con carácter temporal para superar la situación de confrontación y violencia generalizada y establecer condiciones que permitan la reconciliación, restablecer la confianza ciudadana y fortalecer el Estado de Derecho. (...) La justicia en sociedades

N. ${ }^{\circ} 111$, mayo-agosto 2021, págs. 343-374 
identifican las reglas usadas por la Corte, aparece la sentencia C-286 de $2014^{79}$ donde la Corporación señala las características, aspectos y finalidades esenciales de la justicia transicional, a través de las reglas que ha establecido ella misma ${ }^{80}$.

Así mismo, en el desarrollo del proceso de paz con las FARC, y la revisión al Marco Jurídico para la Paz, la Corte Constitucional mediante sentencia C-577 de $2014^{81}$, dio aplicación a la regla creada con la sentencia C-771 de 2011, y posteriormente consolidada con las sentencias C-052 de 2012 y C-579 de 2013. Expone esta Corporación que, en primer lugar, la justicia transicional se encuentra constituida por un conjunto de procesos de transformación política y social en los que se hace necesario usar una gran variedad de mecanismos, cuyo objetivo es lograr la paz y reconciliación, realizar los derechos de las víctimas a la verdad, justicia y reparación, así como restablecer la confianza en las instituciones del Estado, el fortalecimiento de la democracia y otros valores consagrados en la Constitución Política ${ }^{82}$.

De igual manera sucede con la sentencia C-795 de $2014^{83}$, donde se hace notoria la aplicación de las reglas establecidas por la $\operatorname{Corte}^{84}$, pues tiene en cuenta los plant-

en proceso de transición democrática hacia la paz exige un abordaje distinto ante la tensión entre la obligación estatal de impartir justicia y la necesidad de fijar condiciones que permitan la superación del conflicto y la consecución de la paz. Este abordaje en justicia transicional no implica necesariamente la preeminencia de la paz o de la justicia, pues ambos deben ser asumidos en términos de respeto y garantía.»Ibidem.

79 CORTE CONSTITUCIONAL. (2014-B). Sentencia C-286. [M.P. Luis Ernesto Vargas Silva].

${ }^{80}$ «(I) Reconoce la búsqueda de la paz, de la reconciliación, de la confianza pública, el fortalecimiento de la democracia dentro del contexto del Estado Social de Derecho como finalidades y objetivos esenciales de orden constitucional y del Derecho Internacional que constituyen la base justificatoria de los regímenes de justicia transicional de conformidad con la Constitución de 1991 y el Derecho Internacional. (II) Igualmente admite la reincorporación a la vida civil de los actores armados miembros de grupos al margen de la ley como objetivo constitucional de la justicia transicional. (III) Establece los limites a la justicia transicional especialmente centrados en la garantía de los derechos de las víctimas a la verdad, a la justicia, a la reparación, y las garantías de no repetición, con fundamento en la Constitución de 1991 y el Derecho Internacional. (IV) Analiza la constitucionalidad de los mecanismos, estrategias o instrumentos de carácter especial, flexible y transitorio, particularmente de carácter penal, aplicados aún a casos de graves violaciones de Derechos Humanos, como los principios de voluntariedad, alternatividad, oportunidad, selectividad, entre otros, siempre y cuando no se desconozcan, abolan o no se afecten de manera desproporcionada los derechos de las víctimas a la verdad, a la justicia, a la reparación, y las garantías de no repetición. (V) Establece los límites de la aplicación de las disposiciones de carácter transicional para graves violaciones de Derechos Humanos, Derecho Internacional Humanitario, crimenes de lesa humanidad y crimenes de guerra. (VI) Reconoce la necesidad de aplicar el método de ponderación entre los valores, principios y derechos a la paz, y los derechos de las víctimas en procesos de justicia transicional.»Ibidem.

81 CORTE CONSTITUCIONAL. (2014-C). Sentencia C-577. [M.P. Martha Victoria Sáchica Méndez].

82 «De forma similar, la Corte Constitucional ha definido la justicia transicional como »una institución jurídica a través de la cual se pretende integrar diversos esfuerzos, que aplican las sociedades para enfrentar las consecuencias de violaciones masivas y abusos generalizados o sistemáticos en materia de derechos humanos, sufridos en un conflicto, hacia una etapa constructiva de paz, respeto, reconciliación y consolidación de la democracia, situaciones de excepción frente a lo que resultaría de la aplicación de las instituciones penales corrientes". Ibidem.

83 CORTE CONSTITUCIONAL. (2014-D). Sentencia C-795. [M.P. Jorge Iván Palacio Palacio].

84 «(...) el conjunto de herramientas jurídicas, políticas y sociales que se establecen con carácter temporal para superar situaciones de confrontación y violencia generalizada, siendo imprescindible condiciones que permitan el 
eamientos de la C-180 de 2014, que a su vez toma la ratio de sentencia como la C-052 de 2012 y la C-579 de 2013; y, además, tiene en cuenta la C-370 de 2006.

A través de la sentencia C-694 de $2015^{85}$, el alto tribunal, al igual que en fallos anteriores, toma las reglas de la sentencia C-771 de 2011, y sus consolidadoras, para plantear el alcance de la justicia transicional dentro del Estado Social de Derecho ${ }^{86}$. Pero, agrega a estos planteamientos que los Estados deben elaborar un modelo de justicia transicional que responda a las necesidades, y se enfoque no sólo en garantizar la no repetición, la reparación efectiva, el descubrimiento de la verdad, sino propender por la reconciliación.

Como se puede observar, a partir de 2011 con la sentencia C-771, y fallos siguientes como los expuestos C-052 de 2012 y C-579 de 2012, la Corte consolidó un concepto respecto a la justicia transicional, y así mismo, una interpretación de esta categoría en el ordenamiento colombiano, y en algunos fallos posteriores recoge los argumentos de la sentencia C-370 de 2006. Lo anterior, también corresponde al entramado argumental de la C-379 de $2016^{87}$, por medio de la cual se revisó la constitucionalidad del Proyecto de Ley Estatutaria del plebiscito para la refrendación del acuerdo con las FARC, en donde la Corte expresa que no se pueden perder los elementos esenciales establecidos en la jurisprudencia constitucional desde el año $2006^{88}$.

reconocimiento de las víctimas (verdad justicia, reparación y no repetición), el restablecimiento de la confianza ciudadana y la obtención de la reconciliación, en el camino de transición hacia la paz, el fortalecimiento del Estado de derecho y la democracia.»Ibidem.

85 CORTE CONSTITUCIONAL. (2015). Sentencia C-694. [M.P. Alberto Rojas Ríos].

86 «La justicia transicional está constituida por un conjunto de procesos de transformación social y política profunda en los cuales es necesario utilizar gran variedad de mecanismos para resolver los problemas derivados de un pasado de abusos a gran escala, a fin de lograr que los responsables rindan cuentas de sus actos, servir a la justicia y lograr la reconciliación. Esos mecanismos pueden ser judiciales o extrajudiciales, tienen distintos niveles de participación internacional y comprenden sel enjuiciamiento de personas, el resarcimiento, la búsqueda de la verdad, la reforma institucional, la investigación de antecedentes, la remoción del cargo o combinaciones de todos ellos». (...) En similar sentido, la Corte Constitucional ha acogida una definición de justicia transicional según la cual es: "una institución jurídica a través de la cual se pretende integrar diversos esfuerzos, que aplican las sociedades para enfrentar las consecuencias de violaciones masivas y abusos generalizados o sistemáticos en materia de derechos bumanos, sufridos en un conflicto, hacia una etapa constructiva de paz, respeto, reconciliación y consolidación de la democracia, situaciones de excepción frente a lo que resultaría de la aplicación de las instituciones penales corrientes". Ibidem.

87 CORTE CONSTITUCIONAL. (2016-A). Sentencia C-379. [M.P. Luis Ernesto Vargas Silva].

88 La justicia transicional es entendida desde una «(... perspectiva amplia y dirigida a la disposición de diferentes mecanismos jurídicos para la consecución de la paz, la superación del conflicto y, para el caso de algunos Estados, el retorno a la democracia luego de regímenes autoritarios.» Ibidem.

Además, como consecuencia del precedente establecido, la Corporación expone: «La justicia transicional se compone de un grupo de procesos de "transformación social política y profunda «, que comprenden diversos mecanismos dirigidos a lograr la reconciliación y la paz, la vigencia de los derechos de las víctimas y el restablecimiento de la confianza en el Estado, al igual que el fortalecimiento de la democracia. Se trata, entonces, de un conjunto de procesos coordinados que tiene como elemento básico la implementación de cambios políticos que permitan la transición con un componente público participativo.» Ibidem.

Por ende, la finalidad de la justicia transicional no es otra que: «(...) afrontar violaciones masivas de derechos humanos cometidas por agentes del Estado o por particulares. Para ello es necesario adoptar

N. ${ }^{\circ} 111$, mayo-agosto 2021, págs. 343-374 
Para el año 2017, surgen diversos pronunciamientos donde la Corte, más que producir nuevos elementos que integren en concepto de justicia transicional y colaboren con la identificación del alcance de este, se encarga de reiterar lo dicho en fallos precedentes. Este es el caso de la sentencia C-160 de 2017 ${ }^{89}$, donde la Corte trae a colación los argumentos plasmados en los fallos C-577 de 2014 y C-379 de 2016, en los que reconoció, respectivamente, que la justicia transicional corresponde a un conjunto de procesos de transformación política y social en los que se hace necesario usar una gran variedad de mecanismos, cuyo objetivo es lograr la paz y reconciliación, realizar los derechos de las víctimas a la verdad, justicia y reparación, así como restablecer la confianza en las instituciones del Estado, el fortalecimiento de la democracia y otros valores consagrados en la Constitución Política y que las medidas de transición hacia la paz no sólo persiguen la finalización del conflicto, sino que también procuran la reconciliación, la eficacia de los derechos y el fortalecimiento del Estado de Derecho.

De manera similar, sucede con la sentencia C-172 de $2017^{90}$, donde la Corporación toma la ratio de las sentencias C-370 de 2006, C-250 de 2012, C-579 de 2013, C-286 de 2014, C-577 de 2014 y C-379 de 2016, para establecer la naturaleza de las medidas adoptadas en el marco jurídico de la justicia transicional.

Tomando como base la sentencia C-379 de 2016, la Corte reitera sus planteamientos en la C-332 de $2017^{91}$ al establecer los contenidos propios de la justicia transicional en el marco del conflicto armado colombiano; establece que dentro de estos se comprenden un amplio espectro de procesos y mecanismos al interior de la sociedad, que se encuentran dirigidos a la superación de abusos a larga escala sucedidos en el pasado, y con el objetivo de asegurar la rendición de cuentas, el logro de justicia y la reconciliación. Por ello, la transición para la superación del conflicto consiste en la implementación de procesos y mecanismos tanto judiciales y no judiciales.

Por otra parte, en sentencia C-518 de $2017^{92}$ la Corte plantea, frente a la integralidad del proceso de paz con las FARC, que éste debe gravitar en dos aspectos

mecanismos que, en aras de buscar la reconciliación, permitan el equilibrio entre las tensiones que se dan entre la justicia y la paz. Sobre este particular, se ha insistido en la sentencia C-579/13 (...)». Ibidem.

Se advierte que, se identifica en este fallo el elemento de participación ciudadana como parte de la esencia de esta justicia; por ello propone: «El cumplimiento de los fines de las medidas de transición hacia la paz pasa por la acción concurrente y coordinada de diferentes poderes públicos, quienes están investidos de competencias constitucionales para el establecimiento de, inclusive, medidas excepcionales dirigidas a la superación del conflicto armado, en los términos anotados. Estas funciones también son cumplidas por la misma sociedad civil, convocada a través de mecanismos de participación democrática que, como se ha indicado, otorgan mayor estabilidad y legitimidad a los procesos de justicia transicional, en general, y a los acuerdos para la superación del conflicto, en particular.» Ibidem.

89 CORTE CONSTITUCIONAL. (2017-A). Sentencia C-160. [M.P. Gloria Stella Ortiz Delgado].

90 CORTE CONSTITUCIONAL. (2017-B). Sentencia C-172. [M.P. Gloria Stella Ortiz Delgado].

91 CORTE CONSTITUCIONAL. (2017-C). Sentencia C-332. [M.P. Antonio José Lizarazo Ocampo].

92 CORTE CONSTITUCIONAL. (2017-D). Sentencia C-518. [M.P. Antonio José Lizarazo Ocampo]. 
fundamentales: primero, no se circunscribe a un solo asunto, sino que corresponde a un balance de todos los elementos de reforma que garanticen el éxito del proceso y segundo, que todas las medidas conexas son esenciales para la consolidación de la paz $^{93}$, y para el sustento de ello usa los argumentos contemplados en sentencias C-579 de 2013 y C-577 de 2014 sobre los elementos esenciales del concepto de justicia transicional. De manera literal sucede con el pronunciamiento C-541 de $2017^{94}$, en el cual también se le da revisión a la integralidad del proceso de paz, teniendo en cuenta el precedente considerado en la C-518 de 2017. La Corte, en la Sentencia C-555 de 201795, además de la revisión de constitucionalidad del Decreto Ley 895 de $2017^{96}$, imprime la esencia que le ha dado a la justicia transicional a través de sus fallos al sostener allí los argumentos esbozados en sentencias como C-370 de 2006, C-936 de 2010, C-771 de 2011, C-052 de 2012, C-250 de 2012, C-579 de 2013, C-180 de 2014, C-286 de 2014, C-577 de 2014 y C-379 de 2016.

Otro caso similar a los casos expuestos sucede con la sentencia C-565 de 201797, en la cual la Corte aplica las reglas expuestas en las sentencias C-160 y C-172 del mismo año. El último pronunciamiento del año 2017, en relación con el concepto en discusión es la sentencias C- $674^{98}$, por medio del cual se revisa la constitucionalidad del Acto Legislativo 01 de 2017 y por él, la Corporación manifiesta que desde la sentencia C-579 de 2013 se ha pretendido por un modelo de justicia transicional centrado en investigación, juzgamiento y sanción de los máximos responsables fijando mínimos irreductibles en estos deberes, que a su vez, deben ser considerados como elementos esenciales. Por demás se implementan las mismas reglas que en las demás sentencias de este año: C-370 de 2006, C-936 de 2010, C-771 de 2011, C-052 de 2012, C-250 de 2012, C-579 de 2013, C-180 de 2014, C-286 de 2014, C-577 de 2014 y C-379 de 2016.

Frente a la producción de la Corte Constitucional en el año 2018 respecto al concepto de justicia transicional, se encuentra en primer lugar la sentencia C-007 de

93 «La integralidad del proceso gira en torno a dos aspectos. El primero, en cuanto el proceso de paz en Colombia no se concentra en un solo asunto (como podría ser la amnistía), sino en todos los elementos necesarios para la consolidación de la paz, incluyendo reformas institucionales y reformas destinadas a generar los cambios indispensables para la sostenibilidad de los efectos. El segundo significa que todas las medidas conexas con los acuerdos, son igualmente esenciales para el logro de la paz. Por lo tanto, el proceso es uno solo y las medidas son inescindibles, con lo cual se evita, justamente, la desarticulación del proceso y el incumplimiento de ciertos aspectos del Acuerdo. Esto genera confianza en las partes y evita que se desfigure lo pactado.» Ibidem.

94 CORTE CONSTITUCIONAL. (2017-E). Sentencia 541. [M.P. Iván Humberto Escrucería Mayolo].

95 CORTE CONSTITUCIONAL. (2017-F). Sentencia C-555. [M.P. Iván Humberto Escrucería Mayolo].

96 Decreto Ley 895 de 2017, «Por el cual se crea el Sistema Integral de Seguridad para el Ejercicio de la Política».

97 CORTE CONSTITUCIONAL. (2017-G). Sentencia C-565. [M.P. Diana Fajardo Rivera].

98 CORTE CONSTITUCIONAL. (2017-H). Sentencia C-674. [M.P. Luis Guillermo Guerrero Pérez].

(C) UNED. Revista de Derecho Politico

N. ${ }^{\circ} 111$, mayo-agosto 2021, págs. 343-374 
$2018^{99}$, en ella se mantiene la tendencia dada en el año 2017 frente a la utilización de las reglas ya establecidas, sin realizar cambio alguno en el sentido de la línea ${ }^{100}$. Esto de manera idéntica al argumento de la sentencia C-379 de 2016. De manera que, a lo largo del fallo la Corte usa las reglas establecidas en previos como C-370 de 2006, C-936 de 2010, C-771 de 2011, C-052 de 2012, C-250 de 2012, C-579 de 2013, C-180 de 2014, C-286 de 2014, C-577 de 2014, C-694 de 2015 y C-379 de 2016. Lo propio sucede con la sentencia C-025 de $2018^{101}$ donde se plantea, teniendo en cuenta la ratio de las sentencias C-577 de 2014 y C-379 de 2016, que las medidas adoptadas en el contexto de una transición política implican el fortalecimiento de los cometidos estatales plasmados en la Constitución Política ${ }^{102}$. Y donde, por demás, se exponen los argumentos de la sentencia reconceptualizadora de línea: C-771 de 2011. Por otro lado, la sentencia C-027 de $2018^{103}$, por la cual se revisa la constitucionalidad del Acto Legislativo 03 de $2017^{104}$, considera los planteamientos de la C-579 de 2013 frente al elemento de la participación en el marco de la justicia transicional como uno esencial para el fortalecimiento de la democracia y matizando la reconciliación; también ofrece una reinterpretación al alcance de justicia como principio constitucional en el modelo de justicia transicional, y recalca en este sentido que este alcance varía porque implica una evolución en el entendimiento exclusivamente retributivo de la categoría.

Por último, y como punto arquimédico de donde se inició la ingeniería reversa, aparece la sentencia C-080 de $2018^{105}$, a través de la cual se realiza el control automático del Proyecto de Ley Estatutaria de la Jurisdicción Especial para la Paz ${ }^{106}$,

99 CORTE CONSTITUCIONAL. (2018-A). Sentencia C-007. [M.P. Diana Fajardo Rivera].

100 «(...) un conjunto amplio de procesos y mecanismos, judiciales y no judiciales, de carácter excepcional y transitorio, que responden a largos periodos de violencia generalizada, en los que se han cometido constantes violaciones de derechos bumanos y al derecho internacional bumanitario. Los propósitos de la justicia transicional son: (i) responder a la violencia generalizada y, por ende, asegurar el derecho a la paz; (ii) garantizar los derechos de las víctimas a la verdad, la justicia, la reparación y la no repetición de los hechos violentos; (iii) fortalecer al Estado de derecho y a la democracia; $y$ (iv) promover la reconciliación social.»Ibidem.

101 CORTE CONSTITUCIONAL. (2018-B). Sentencia C-025. [M.P. José Fernando Reyes Cuartas].

102 «La Corte evidenció que las medidas de transición hacia la paz tienen una perspectiva amplia que va más allá de la finalización del conflicto armado, al tener como objetivos principales la reconciliación, la eficacia de los derechos y el fortalecimiento del Estado participativo y democrático de derecho. (...) previó un conjunto de reglas en materia de instrumentos de justicia transicional que deben tenerse en cuenta para la correcta comprensión de la legislación que la materializa y desarrolla.» Ibidem.

103 CORTE CONSTITUCIONAL. (2018-C). Sentencia C-027. [M.P. José Fernando Reyes Cuartas].

104 Acto Legislativo 03 de 2017, «por medio del cual se regula parcialmente el componente de reincorporación política del Acuerdo Final para la Terminación del Conflicto y la Construcción de una Paz Estable y Duradera por medio del cual se regula parcialmente el componente de reincorporación política del Acuerdo Final para la Terminación del Conflicto y la Construcción de una Paz Estable y Duradera».

105 CORTE CONSTITUCIONAL. (2018-D). Sentencia C-080. [M.P. Antonio José Lizarazo Ocampo].

106 En Colombia los proyectos de ley estatutaria tienen control previo de constitucionalidad. Finalmente, después del examen de constitucionalidad dicho proyecto se convirtió en la Ley Estatutaria 
en donde la Corte, de conformidad con los precedentes establecidos, señaló que la búsqueda de la superación entre las tensiones entre los principios de justicia y de paz, corresponden a la finalidad principal de la justicia transicional ${ }^{107}$. Así mismo, resalta los elementos centrales del modelo de justicia transicional, que a su vez constituyen aquellos que son esenciales para entender el alcance del concepto, entre ellos: la paz, verdad, justicia, reparación y garantía de no repetición, derechos de las víctimas, estructuración de una jurisdicción separada de la ordinaria y procedimiento especial, administración de justicia de manera transitoria, es decir, temporalidad, cumplimiento con los deberes de investigar, juzgar y sancionar; todos ellos, elementos provenientes de los fallos expuestos en los argumentos de la línea aquí expuesta.

En consecuencia, siguiendo la metodología de construcción de línea jurisprudencial de López Medina esbozada en páginas precedentes, la línea jurisprudencial que recoge el devenir del concepto de justicia transicional en la jurisprudencia constitucional colombiana, se grafica de la siguiente manera:

\begin{tabular}{|clll|}
\hline Convenciones & & \\
$\triangle$ & Fundadora & Consolidadora \\
$\square$ & Dominante & & P. Arquimédico \\
$\nabla$ & Reconceptualizadora & & Desvío con intento de modificación \\
\hline
\end{tabular}

1957 de 2019, «Estatutaria de la Administración de Justicia en la Jurisdicción Especial para la Paz».

107 La justicia transicional busca solucionar las fuertes tensiones que se presentan entre la justicia y la paz, entre los imperativos jurídicos de satisfacción de los derechos de las víctimas y las necesidades de lograr el cese de hostilidades, para lo cual busca cumplir con tres criterios cuya importancia es reconocida dentro de nuestra Constitución: la reconciliación, el reconocimiento de los derechos de las víctimas y el fortalecimiento del Estado Social de Derecho y de la Democracia. Por lo anterior, lejos de sustituir el pilar fundamental de la garantía de los derechos bumanos, la justicia transicional es un desarrollo del mismo en situaciones de violaciones masivas a los derechos bumanos en las cuales la utilización de mecanismos ordinarios puede obstaculizar la salvaguarda de ésta. CORTE CONSTITUCIONAL. (2018-D); ob. cit.

(C) UNED. Revista de Derecho Politico

N. ${ }^{\circ} 111$, mayo-agosto 2021, págs. 343-374 


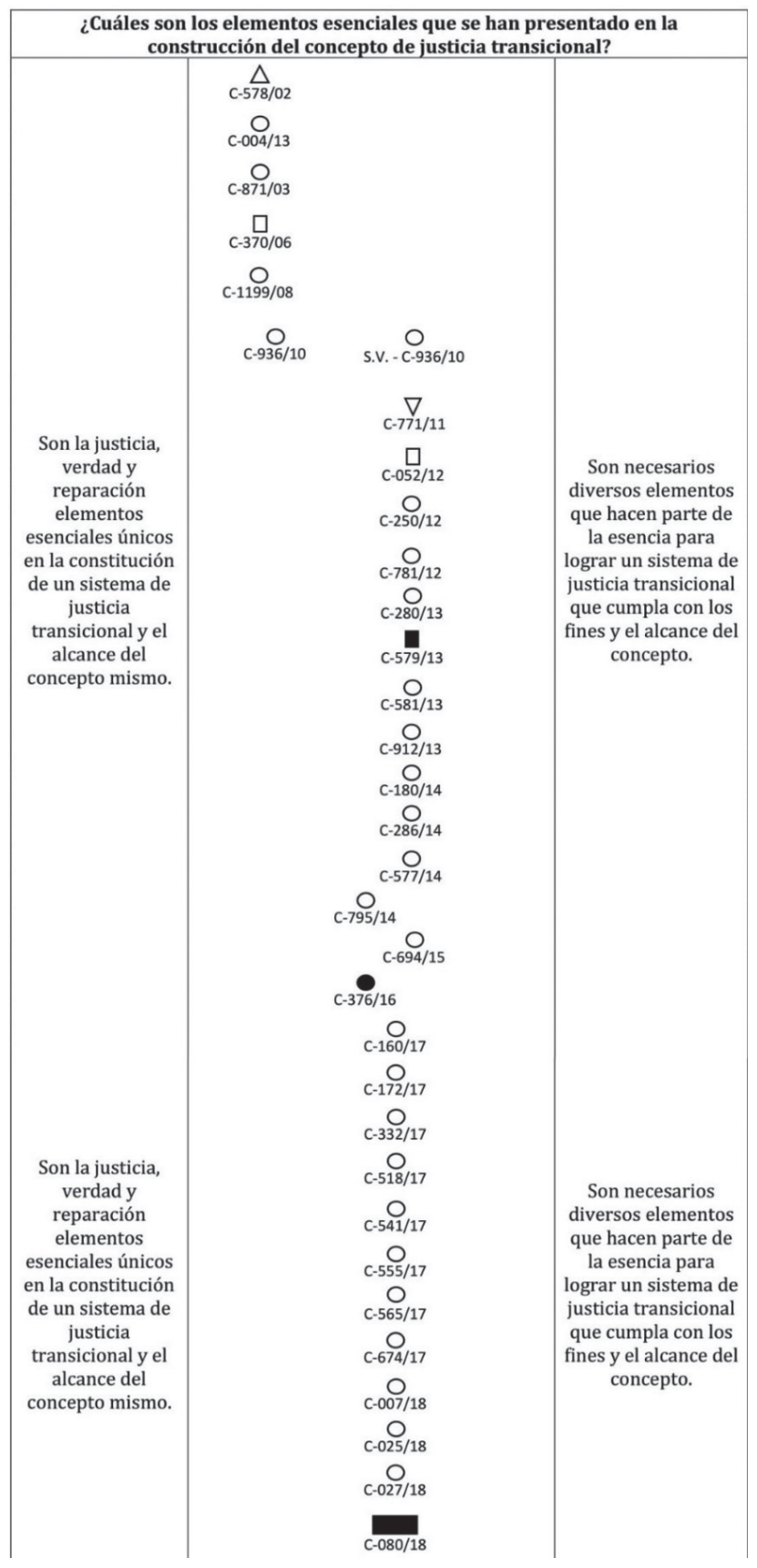

Fuente: Elaboración propia. 


\section{CONCLUSIONES}

En un principio, la justicia transicional hizo su arribo al campo jurídico colombiano a través de la Ley 975 de 2005, conocida como Ley de Justicia y Paz, mediante la cual se pretendió dotar de un asidero jurídico el proceso de desmovilización adelantado, en ese entonces, con los paramilitares federados en las AUC (Autodefensas Unidas de Colombia).

En un momento posterior, la justicia transicional sufrió un proceso de constitucionalización, primero, a partir de su abordaje por la jurisprudencia constitucional y luego con la inclusión de Actos Legislativos de reforma constitucional. El papel de la jurisprudencia constitucional fue fundamental para la configuración del soporte jurídico para el Acuerdo Final con las FARC — EP (Fuerzas Armadas Revolucionarias de Colombia - Ejército del Pueblo), en donde uno de sus principales aportes fue garantizar la vigencia del mismo aún con el cambio de gobierno, lo cual permitió garantizar que se mantuviera la columna vertebral del Acuerdo que es la Jurisdicción Especial para la Paz (JEP).

Las reformas constitucionales derivadas del Acuerdo con las FARC, gozaban de control automático de constitucionalidad por parte de la Corte Constitucional, es decir, una vez adoptadas debían pasar directamente a la Corte para su análisis, y es ahí donde la jurisprudencia constitucional termina dotando de fundamentación teleológica al modelo de justicia transicional pactado, para lo cual recoge su jurisprudencia dada hasta el momento sobre la materia y le fija un nuevo alcance, ligando a la justicia transicional como una garantía que permite la satisfacción de los derechos fundamentales de las víctimas a la verdad, la justicia, la reparación y las garantías de no repetición. La justicia transicional, entonces, pasa de ser una ley de beneficios punitivos, como se planteó inicialmente la Ley de Justicia y Paz (Ley 975 de 2005), a un modelo de justicia con soporte constitucional, en las reformas dadas por cuenta del Acuerdo Final con las FARC, y a una garantía para la satisfacción de unos derechos, debido a la intervención de la jurisprudencia constitucional, quien fijó el alcance de esta.

\section{BIBLIOGRAFÍA}

\section{Referencias bibliográficas}

Ambos, K. (2009). «El marco jurídico de la justicia de transición». En AMBOS, Kai, MALARINO, E. y ELSNER, G. (Editores), Justicia de Transición. Informes de América Latina, Alemania, Italia y España, pp. 23-129. Montevideo: Konrad Adenauer Stiftung. Disponible en: https://www.kas.de/c/document_library / get_file? uuid $=$ c6012f10-4557-5aa7-12dc-cac8ef7c350f\&groupId $=252038$ 
Ambos, K. y Zuluaga, J. (2014). «Justicia de transición y Constitución. A manera de introducción». En AMBOS, K. (Coordinador), Justicia de transición y Constitución. Análisis de la sentencia C-579 de 2013 de la Corte Constitucional. Temis Editorial, págs. 1-19.

BARZOTTO, L. (2013). «Positivismo, neoconstitucionalismo y activismo judicial». En MORA, G. y BENÍTEZ, V. (Coordinadores), Retos del derecho constitucional contemporáneo. Editorial Astrea, págs. 51-78.

GonZÁlez Quintero, R. y Moreno Ortíz, L. J. (2018). «Funciones secundarias de la Corte Constitucional colombiana: una aproximación a la decisión sobre excusas a los emplazamientos cursados por el Congreso», Revista de Derecho Político, No. 102, pp. 373-401.

Grández Castro, P. (2016). El Ascenso de los principios en la práctica constitucional, Lima, Palestra Editores.

López Cuéllar, N. (2015). Pluralismo jurídico estatal: entre conflicto y diálogo. Enseñanzas de un caso colombiano, Bogotá D.C., Universidad del Rosario.

López Medina, D. E. (2016). Eslabones del Derecho. El deber de coberencia con el precedente judicial, Bogotá D.C., Legis.

López Medina, D. E. (2007). El derecho de los jueces, segunda edición, tercera reimpresión, Bogotá D.C., Legis.

López Medina, D. E. (2006). Interpretación constitucional, Bogotá D.C., Consejo Superior de la Judicatura.

Montoya Medina, L. E. (2016). El imperio de la jurisprudencia, Bogotá D.C., Grupo Editorial Ibáñez.

Pérez Toro, W. F. (2000). «Guerra y delito en Colombia», Revista Estudios Políticos, No. 12, pp. 11-41. Disponible en: https://aprendeenlinea.udea.edu.co/ revistas/index.php/estudiospoliticos/article/view/16702/14482

Quinche Ramírez, M. F. (2017). Reformismo constitucional, Bogotá D.C., Grupo Editorial Ibáñez.

Quinche Ramírez, M. F. (2014). El precedente judicial y sus reglas, Bogotá D.C., Legis.

Quinche Ramírez, M. F. (2010). Vias de hecho: acción de tutela contra providencias judiciales, sexta edición, Bogotá D.C., Ediciones Doctrina y Ley Ltda.

Rúa Delgado, C. F., Duarte Molina, T. M. y Gómez Morales, L. F. (2018). «Escenarios para el sometimiento de excluidos de Justicia y Paz a la Jurisdicción Especial para la Paz: disquisición sobre sus ámbitos de aplicación», Revista opinión Jurídica, Vol. 17, No. 35, pp. 117-146. Disponible en: https://revistas.udem. edu.co/index.php/opinion/article/view/2783/2568

Rúa Delgado, C. F. (2017). «Hermenéutica de la justicia transicional en Colombia: una lectura desde la teoría de los momentos de Lefebvre», Revista de Derecho Migratorio y Extranjería, No. 44, pp. 137-151.

Rúa Delgado, C. F. (2016). «La justicia anamnética como construcción complementaria del paradigma de justicia transicional. Una mirada desde el caso 
colombiano», Revista ius et Praxis, Vol. 22, No. 1, pp. 455-492. Disponible en: http://www.revistaiepraxis.cl/index.php/iepraxis/article/view/629/436

Rúa Delgado, C. F. (2015). «Los momentos de la justicia transicional en Colombia», Revista de Derecho, No. 43, pp. 71-109. Disponible en: http://rcientificas. uninorte.edu.co/index.php/derecho/article/view/6270/6745

Rúa Delgado, C. F. (2014). «Prolegómenos para la aplicación de criterios de priorización de delitos en los procesos de Justica y Paz en Colombia», Revista Latinoamericana de Derechos Humanos, Vol. 25, No. 2, pp. 193-220. Disponible en: https://www.revistas.una.ac.cr/index.php/derechoshumanos/article/ view/6159/6142

Sierra Cadena, G. (2009). El juez constitucional: un actor regulador de las políticas públicas, Bogotá D.C., Universidad del Rosario.

Title

Transitional justice as constitutional category in Colombia

Summary:

Introduction. 1. The analysis of the constitutional precedent. 2. The concept of transitional justice in Colombian constitutional jurisprudence. 3. Conclusions. Bibliography.

\section{Resumen}

Este artículo pretende analizar la jurisprudencia constitucional colombiana referente a la justicia transicional, utilizando para ello la metodología de análisis del precedente constitucional esbozado por Diego López Medina, con el fin de revisar la forma en cómo la jurisprudencia ha permitido cimentar a la justicia transicional como una categoría constitucional, en donde ésta ha jugado un papel fundamental a través de la fijación del alcance de la misma, como una garantía superior que permite la defensa de los derechos de las víctimas.

\section{Abstract}

This text refers to Colombian constitutional jurisprudence about transitional justice. It uses the method named precedent analysis by Diego López Medina. The purpose is the study about transitional justice like a constitutional category and the role of the precedent for the defense of the victim's rights. 
Palabras clave

Jurisprudencia constitucional; análisis de precedente; línea jurisprudencial; justicia transicional.

\section{Key words}

Constitutional jurisprudence; precedent analysis; case-law line; transitional justice. 
